\title{
Effects of Swirling Strength of the Premixed Gas Flow on Pollutant Emission in a Heavy-Duty Gas Turbine
}

\author{
Huanhuan $\mathrm{Gao}^{1}$, Zaiguo Fu ${ }^{1}{ }^{*}$, Zhuoxiong Zeng ${ }^{1}$, Jiang Liu ${ }^{1}$ and Peifen Weng ${ }^{1}$ \\ ${ }^{1}$ College of Energy and Mechanical Engineering, Shanghai University of Electric Power, Shanghai 200090, China
}

\begin{abstract}
The combustion process and pollutant emission of an annular combustion chamber for a heavy-duty gas turbine were investigated by numerical method. The realizable $k$ - $\varepsilon$ model and finite rate/eddy dissipation model were adopted for calculations of turbulence and combustion. The effects of different swirling numbers of the double-swirler inlet on the temperature distribution and the thermal $\mathrm{NO}_{\mathrm{x}}$ formation in the combustion chamber were analyzed. The results show that the change of the swirling number of the outer swirling flow has a greater influence on the generation of the thermal $\mathrm{NO}_{\mathrm{x}}$ when compared with that of the inner swirling flow. The maximum average temperature of the central cross section of the combustor does not exceed $1760 \mathrm{~K}$. The average mass fraction of the generated thermal $\mathrm{NO}_{\mathrm{x}}$ at the exit decreases with the increasing outer swirling number. When the outer swirling number is less than 0.8 , the generation of the thermal $\mathrm{NO}_{\mathrm{x}}$ is severe at the side wall of the combustion chamber.
\end{abstract}

\section{Introduction}

With the progress of human science and technology and the rapid development of society, environmental problems are becoming increasingly concerned. Equipment manufacturing industry not only pursues high efficiency and high profit, but also pays attention to the environmental protection. For gas turbine, the pollutants emission of combustion chamber must be taken into account in addtion to its high efficiency and stable combustion in power generation. It is understood that the most widely employed method is using the Dry Low- $\mathrm{NO}_{\mathrm{x}}$ (DLN) emission combustion technology. It reduces $\mathrm{NO}_{\mathrm{x}}$ emission by reducing the temperature of combustion area through lean combustion premix combustion [1].

In addition, the adopted DLN technology is always combined with the method of stabilizing combustion such as using the swirling flow. It can promote the mixing of hot and cold gas in the combustion chamber in addition to stabilization of combustion. This swirling flow has an important impact on the temperature of the combustion chamber, and thereby affects the generation and emission of pollutant $\mathrm{NO}_{\mathrm{x}}$. In the literature [2], it was pointed out that the larger the recirculation zone caused by swirling flow is, the longer the residence time of high-temperature gas in the recirculation zone is. As a result, more $\mathrm{NO}_{\mathrm{x}}$ were generated.

With respect to the study of the effects of inlet swirling number on pollutant generation, Shi et al. [3] investigated the changes of combustion instability and $\mathrm{NO}_{\mathrm{x}}$ formation in a combustion chamber. The results showed that the entrainment capacity of the combustion products increased, the range of the central recirculation zone and the high temperature zone expanded, and the
$\mathrm{NO}_{\mathrm{x}}$ emission volume fraction decreased after the swirling number increased. Moreover, some researchers studied the influence of other factors on pollutant emission in the combustion chamber [4-7]. The factors include the adopted fuel such as the micro-mixed hydrogen, the ratio of fuel to air, the equivalence ratio in a multistage combustor, the flow parameter of fuel jet and the inlet gas temperature etc. However, the swirling flow from a hybrid swirler is more complicated and it is still a question worthy to further discuss, especially for a heavy-duty gas turbine.

In order to ascertain the effects of inlet swirling strength on the pollutant emission in a combustor, we study numerically the combustion process in an annular combustion chamber of a heavy-duty gas turbine with hybrid swirlers. The physical model, the mathematical model and the detailed results on temperature distribution and generation of thermal $\mathrm{NO}_{\mathrm{x}}$ affected by the inner and outer swirling numbers are introduced successively.

\section{Modeling}

\subsection{Physical model}

The research object in present study is a three-dimensional (3D) annular combustor for a heavy-duty gas turbine. The following assumptions have been made to simplify the simulation and accelerate the convergence of the calculation: (1) the blade structure of swirler is ignored and the double-swirler inlet is with an inner round hole and a concentric annular hole; (2) the micro mixing holes on the combustor wall are ignored.

\footnotetext{
* Corresponding author: fuzaiguo@shiep.edu.cn
} 
There are 24 hybrid inlets uniformly distributed on the entire arc end face of the combustion chamber. In order to accelerate the calculation speed, we selected $1 / 24$ of the entire combustion chamber as the calculation domain. As shown in Figure 1, the double-swirler inlet is composed of an inner round hole and a concentric annular hole. The diameter of the inner hole is $0.084 \mathrm{~m}$ $(2 \mathrm{R}, \mathrm{R}=0.042 \mathrm{~m})$. The annular hole is $1.5 \mathrm{R}$ wide. The total length of the combustor is $30.8 \mathrm{R}$ and the height of the annular outlet is $3.4 \mathrm{R}$.

The other main geometric parameters are shown in Figure 2. Several characteristic lines perpendicular to the central axis of the combustor on the central cross section are marked. The corresponding characteristic section perpendicular to the central axis crossing the characteristic line can be obtained.

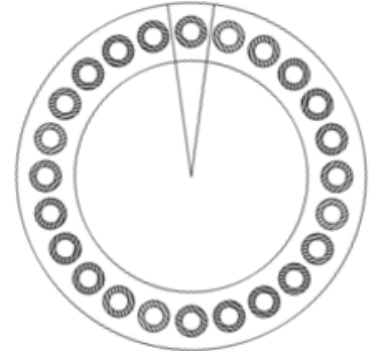

Fig. 1. Schematic diagram of the arc end face of the combustor.

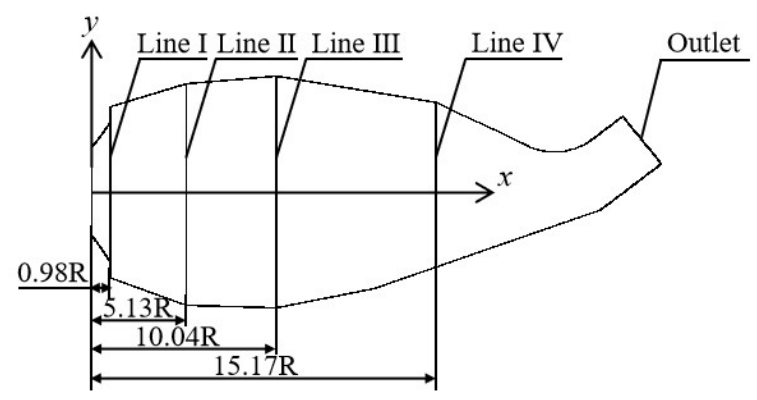

Fig. 2. Schematic diagram of the central cross section of the combustor.

\subsection{Grids}

The software of ICEM CFD 15.0 was employed to mesh the computational domain $(1 / 243 \mathrm{D}$ combustor). The grid of the swirling inlet is locally refined in order to ensure the accuracy of the calculation results. The grids near the combustor wall are also refined to accurately capture the abrupt changes of physical parameters.

Four sets of grids with the number of 1.19 million, 1.64 million, 2.02 million and 2.46 million were adopted to conduct grid independence validation, The results of the reacting flow in the combustor under the same working condition using the four sets of grids are compared. Figure 3(a), 3(b) shows the axial velocity and mass fraction of $\mathrm{O}_{2}$ at different radial positions on the characteristic section of Line I, respectively.

It can be seen from Figure 3 that the predicted results by using 2.02 million grids are very close to those by using 2.46 million grids. Thus, the number of 2.02 million is considered to be an acceptable number of grids for the calculations in present study.

\subsection{Mathematic model}

The thermal $\mathrm{NO}_{\mathrm{x}}$ dominates the pollutant under the high-power output condition of gas turbine. Thus, the formation of the thermal $\mathrm{NO}_{\mathrm{x}}$ is predicted by a set of chemical reactions known as the extended Zeldovich mechanism $[8,9]$.

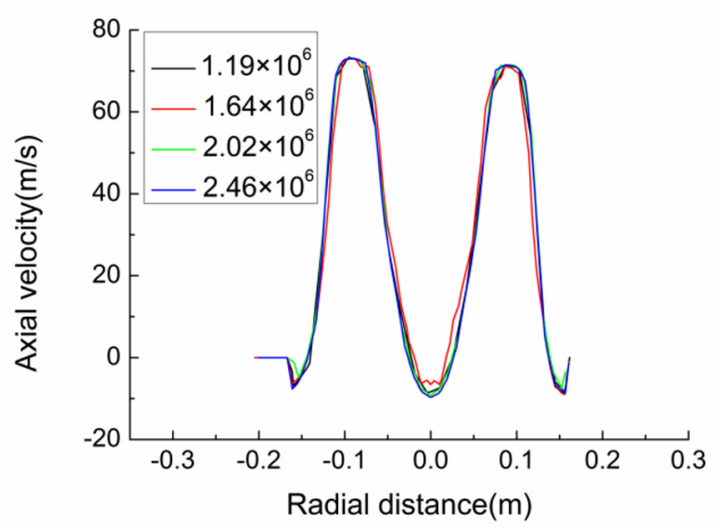

(a) Axial velocity

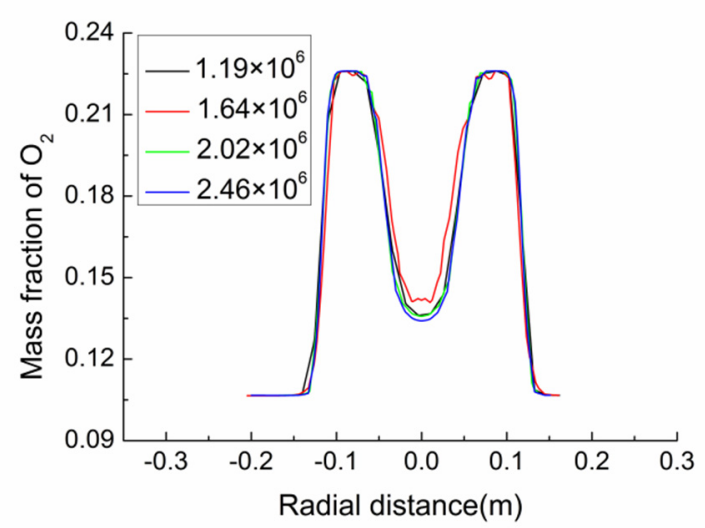

(b)Mass fraction of $\mathrm{O}_{2}$

Fig. 3. Predicted axial velocity and mass fraction of $\mathrm{O}_{2}$ on the characteristic section of Line I under various grid numbers.

The realizable $k-\varepsilon$ model is adopted since it adds rotation and curvature related terms to the turbulent viscosity calculation formula. The turbulent kinetic energy of the realizable $k-\varepsilon$ model and its dissipation rate transport equation are given as follows.

$$
\begin{gathered}
\rho \frac{d k}{d t}=\frac{\partial}{\partial x_{i}}\left[\left(\mu+\frac{\mu_{t}}{\sigma_{k}}\right) \frac{\partial k}{\partial x_{i}}\right]+G_{k}+G_{b}-\rho \varepsilon-Y_{M} \\
\rho \frac{d \varepsilon}{d t}=\frac{\partial}{\partial x_{i}}\left[\left(\mu+\frac{\mu_{t}}{\sigma_{\varepsilon}}\right) \frac{\partial \varepsilon}{\partial x_{i}}\right]+\rho C_{1} S \varepsilon-\rho C_{2} \frac{\varepsilon^{2}}{k+\sqrt{v \varepsilon}}+C_{1 \varepsilon} \frac{\varepsilon}{k} C_{3 \varepsilon} G_{b}
\end{gathered}
$$




$$
\mu_{\mathrm{t}}=\rho c_{\mu} \frac{k^{2}}{\varepsilon}
$$

In the above three equations, $G_{k}$ represents the generation of turbulent energy caused by the average velocity gradient. $G_{b}$ represents the generation of turbulent energy due to the influence of buoyancy. $Y_{M}$ represents the effect of compressible turbulent pulsation expansion on the total dissipation rate. $C_{1 \varepsilon}$ and $C_{3 \varepsilon}$ are constants. $\sigma_{k}$ and $\sigma_{z}$ are the turbulent Prandtl constants of turbulent kinetic energy and its dissipation rate. $S$ is the swirling number. $\mu_{\mathrm{t}}$ is the turbulent viscosity. $c_{\mu}$ is a function of the average strain rate and the swirling strength.

Based on the two-step reaction of methane, it is considered that the fuel and air are completely premixed when setting the intake boundary condition of the swirler inlet. The premixed combustion occurs in the annular combustion chamber. The combustion model is a finite rate/vortex dissipation turbulent combustion model. The rate and eddv dissination rate are calculated as follows.

$$
\begin{gathered}
R_{i, r}=v_{i, r}^{\prime} M_{w, i} A B \rho \frac{\varepsilon}{\kappa} \frac{\sum_{p} Y_{p}}{\sum_{j}^{N} v_{j, r}^{\prime \prime} M_{w, j}} \\
W=k C_{A}^{a} C_{B}^{b}=k_{0} \exp \left(-\frac{E}{R T}\right) C_{A}^{a} C_{B}^{b}
\end{gathered}
$$

In Equations (4) and (5), $\varepsilon / k$ controls the reaction rate. $K$ is the pre-factor. $E$ is the activation energy. $C$ is the reactant concentration. $R$ is the gas constant. $T$ is the temperature. $Y_{p}$ is the mass fraction of the product. $M_{w, i}$, $M_{w, j}$ are the molecular weights of the substances in the $i$, j. $A$ and $B$ are empirical constants as 4.0 and 0.5 , respectively. $\rho$ is the density. $V_{i, r}{ }_{i}$ is the stoichiometric number of the reactant $i$ in the reaction $r . V^{\prime \prime}{ }_{i, r}$ is the reaction $r$ the stoichiometric number of the product $i$.

The swirling number of the double-swirler inlet is defined as the ratio of the rotational angular momentum to the axial angular momentum. According to the practical settings for the inlet, the swirling number is given as:

$$
S=\frac{2 W}{3 U}
$$

In the equation, $S$ is swirling number; $U$ is axial velocity; $W$ is tangential velocity.

Table 1. Conditional parameters of the swirling inlet.

\begin{tabular}{|c|c|c|}
\hline Physical quantity & Inner round hole & Outer annular hole \\
\hline $\begin{array}{c}\text { Mass flow } \\
\text { rate(kg/s) }\end{array}$ & 44.64 & 479.52 \\
\hline Equivalence ratio & 0.36 & 0.53 \\
\hline Swirling number & $0.4-1.2$ & $0.4-1.2$ \\
\hline $\begin{array}{c}\text { Gas temperature } \\
(\mathrm{K})\end{array}$ & 697.24 & 697.24 \\
\hline
\end{tabular}

\subsection{Boundary conditions}

The inlet boundary conditions are set in the local cylindrical coordinate system to determine the axial and tangential velocity, respectively. The outlet is set as a pressure outlet with the pressure of $1823900 \mathrm{~Pa}$. The combustor side wall is adiabatic. The bilateral wall of the computational domain is periodic boundary. The pressure and velocity coupling used SIMPLE algorithm and the standard wall method was adopted near wall. The adopted fuel is pure methane $\left(\mathrm{CH}_{4}\right)$. The other conditional parameters of the double-swirler inlet are listed in Table 1.

\section{Results and discussions}

\subsection{Effects of inner swirling number}

The variation of the average temperature of three sections in the combustor under different swirling numbers of the inlet gas flow from the inner round hole is shown in Figure 4. Here, the swirling number of the inlet gas flow from the outer annular hole is fixed at 0.8 . It can be seen that the average temperature of the characteristic section of Line II and the central section increase with the inner swirling number. But the average temperature of the outlet section decreases slightly. When the inner swirling number is within the range of $0.6 \sim 1.0$, the average temperature of the central cross section rises slowly. When the inner swirling number is 1.2 , the average temperature on the central cross section rises to the maximum value as $1759 \mathrm{~K}$. It is reasonable according to the designed value introduced in reference [3].

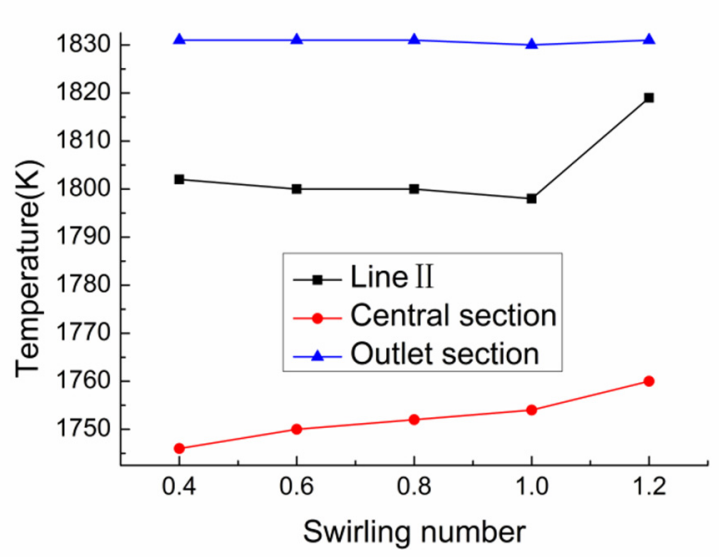

Fig. 4. The variation of average temperature of different sections under different inner swirling numbers.

The molar fraction isolines of the generated thermal $\mathrm{NO}_{\mathrm{x}}$ of the characteristic section of Line II in the chamber under various inner swirling numbers is shown in Figure 5. It can be seen that the molar fraction of thermal $\mathrm{NO}_{\mathrm{x}}$ in the central region is very uniform due to the strong recirculation there. It decreases with the increase of the swirling number. However, there are large differences around the upper and lower boundaries. The distribution of molar fraction has an obvious gradient. Due to the effects of angular recirculation, a 
high temperature environment is formed due to the accumulated heat. This provides the condition for thermal $\mathrm{NO}_{\mathrm{x}}$ generation. Therefore, there are more thermal $\mathrm{NO}_{\mathrm{x}}$ produced at the side walls.

The average mass fraction of thermal $\mathrm{NO}_{\mathrm{x}}$ of the outlet section under different inner swirling numbers is shown in Figure 6. It can be seen that the average mass fraction has a slight fluctuation with the increase of swirling number. The overall trend is decreasing with the increase of swirling number. The average mass fraction is around $3.5 \times 10^{-6}$.

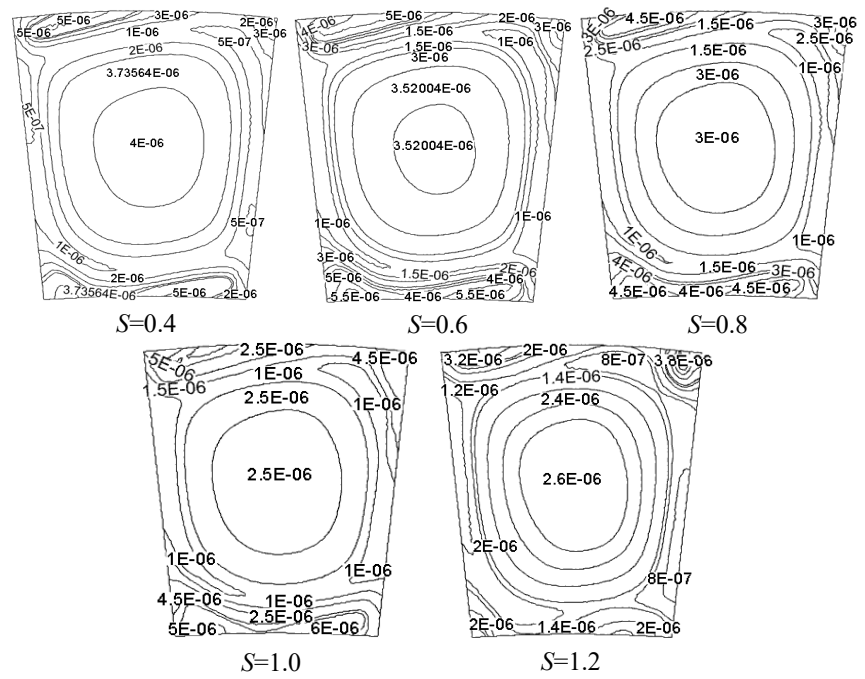

Fig. 5. The molar fraction isolines of thermal $\mathrm{NO}_{\mathrm{x}}$ of the characteristic section of Line II under various inner swirling numbers.

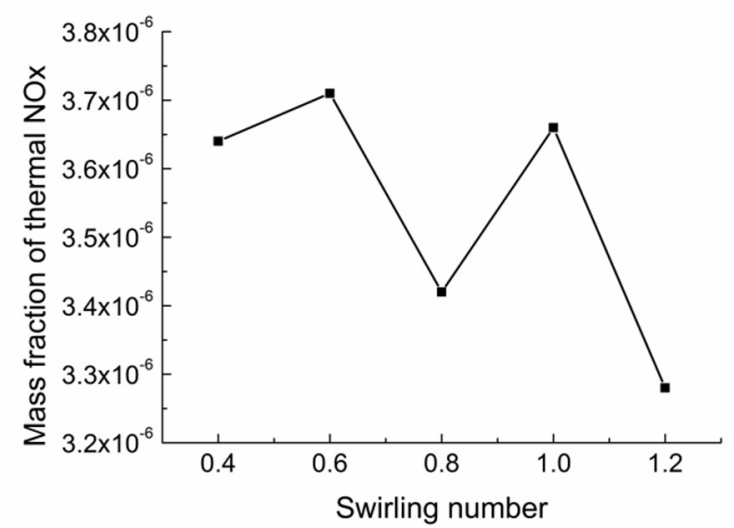

Fig. 6. Average mass fraction of thermal $\mathrm{NO}_{\mathrm{x}}$ of the outlet section under different inner swirling numbers.

\subsection{Effects of outer swirling number}

The variation of the average temperature of three sections in the combustor under different swirling numbers of the inlet gas flow from the outer round hole is shown in Figure 7. Here, the swirling number of the inlet gas flow from the inner annular hole is fixed at 0.8 . It can be seen that the average temperature of the central cross section increases slightly with the increase of the outer swirling number. When the outer swirling number is within the range of $0.6 \sim 1.0$, the average temperature of the characteristic section of Line II rises rapidly. However, the average temperature of the outlet section is almost unchanged with the increase of outer swirling number. When the swirling number of the outer ring is 1.2 , the average temperature of the central cross section is $1760 \mathrm{~K}$. At this point, the formation rate of thermal $\mathrm{NO}_{\mathrm{x}}$ is $6.09 \times 10^{-7} \mathrm{kgmol} /\left(\mathrm{m}^{3} \cdot \mathrm{s}\right)$.

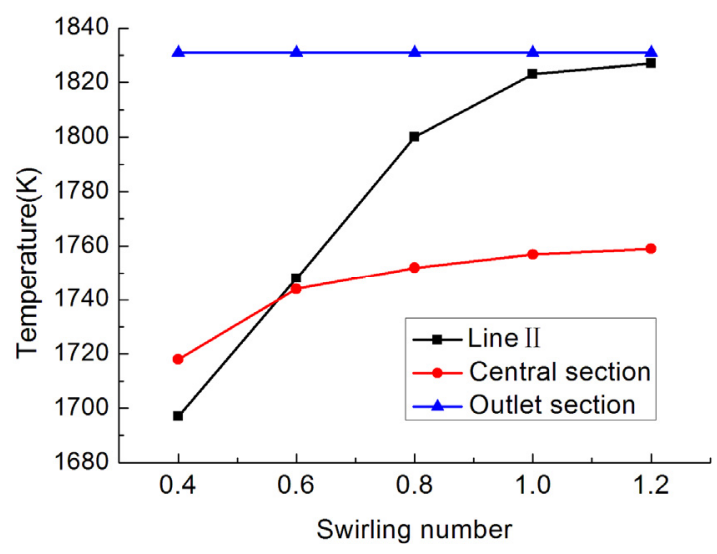

Fig. 7. The variation of average temperature of different sections under different outer swirling numbers.

The molar fraction isolines of generated thermal $\mathrm{NO}_{x}$ of the characteristic section of Line II in the chamber under various outer swirling numbers is shown in Figure 8. It can be seen that the molar fraction of thermal $\mathrm{NO}_{\mathrm{x}}$ in the central region is very uniform for each case due to the strong recirculation there. The changing trend of the magnitude is not distinct. Under the conditions at low swirling numbers less than 0.8 , the molar fraction around the upper and lower boundaries caused by trapped vortex are relatively large. It can be speculated that a lot of heat are accumulated in the angular recirculation zone. This results in a high temperature environment at the side wall, which provides the conditions for the generation of thermal $\mathrm{NO}_{\mathrm{x}}$.

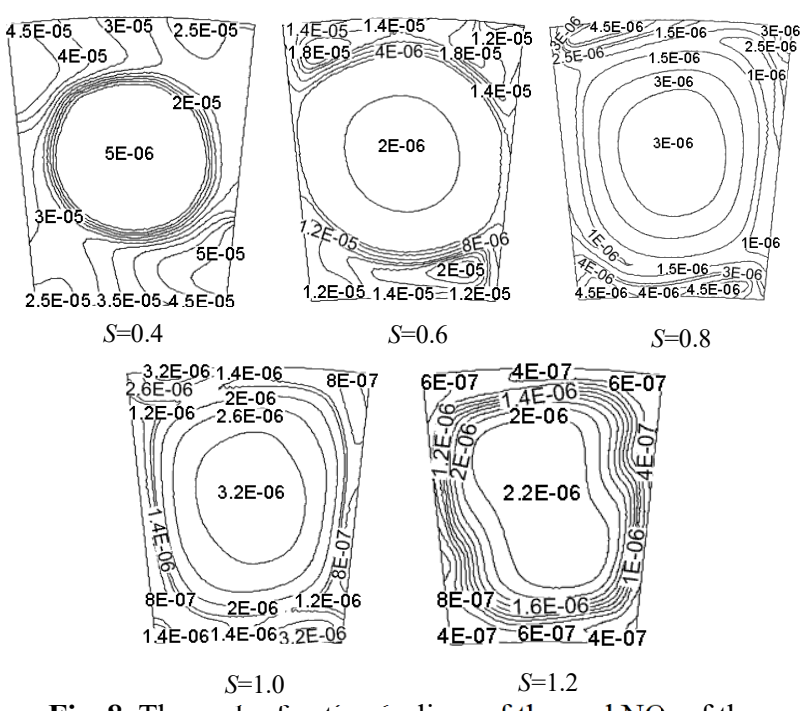

Fig. 8. The molar fraction isolines of thermal $\mathrm{NO}_{\mathrm{x}}$ of the characteristic section of Line II under various outer swirling numbers. 


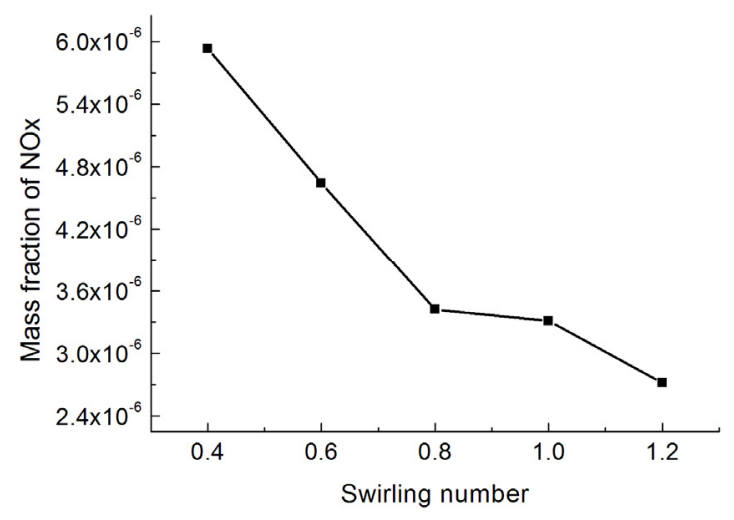

Fig. 9. Average mass fraction of thermal $\mathrm{NO}_{\mathrm{x}}$ of the outlet section under different outer swirling numbers.

The average mass fraction of thermal $\mathrm{NO}_{\mathrm{x}}$ on the outlet section is shown in Figure 9. It can be seen that the average mass fraction decreases with the increase of the outer swirling number. The average mass fraction at $S=1.2$ becomes the smallest as the value of $2.7 \times 10^{-6}$. This value is only half that at $S=0.4$.

Moreover, it is concluded that the change of the outer swirling number has a greater impact on the temperature distribution and generation of thermal $\mathrm{NO}_{\mathrm{x}}$ in the combustor than the inner swirling number by comparison between the results in above two sections. This difference should be attributed to the mass flux distribution of the double-swirler inlet. The swirling flow from the outer annular hole with a relatively large discharge may dominate the thermal performance of the combustor.

\section{Conclusions}

This study focuses on the effects of the swirling strength of a hybrid inlet swirling flow on the pollutant emission for a self-designed heavy-duty gas turbine annular combustor. The following conclusions are addressed:

(1) The impact trend of the inner and outer swirling numbers on the temperature of the central cross section of the combustor is same. The maximum average temperature does not exceed $1760 \mathrm{~K}$. However, the effect of the outer swirling number on the pollutant emission is greater than the inner swirling number.

(2) At the exit section of the combustor, the mass fraction of the generated thermal $\mathrm{NO}_{\mathrm{x}}$ decreases with the increasing outer swirling number. In the recirculation region, the molar fraction of thermal $\mathrm{NO}_{\mathrm{x}}$ is large at the side wall when the outer swirling number is less than 0.8 . The average value increases with the decrease of swirling number rapidly.

\section{Acknowledgement}

The supports by the National Science Foundation of China (NO.51606114) and Science and Technology Commission of Shanghai Municipality (STCSM NO.16020500700) to this study are acknowledged and highly appreciated.

\section{References}

1. A.H. Lefebvre. Philadelphia, Taylor \& Francis Press, (1998).

2. Y.Z. Lin, Q.H. Xu, G. Liu. National Defense Industry Press, (1999).

3. L. Shi, Z.G. Fu, R.X. Wang, Y.Z. Shen. J. Chin. Society of Power Eng. 37(9), 691-698 (2017).

4. A.H. Ayed, A.K. Kusterer, H.H.W. Funke, J. Keinz, C. Striehan, D. Bohn. Propulsion and Power Research, 4(3), 123-131(2015).

5. B. Ge, Y.B. Ji, Z.L. Zhang, Sh. Zang, Y.Sh. Tian, Hai Yu, M. Chen, G. Jiao, D.F. Zhang. Int. J. Hydrogen Energy, 44, 4023-4031 (2019).

6. D.S.D. Almeida, P.T. Lacava. Energy Procedia, 66, 117-120 (2015).

7. A. Elkady, S.M. Jeng, H. Mongia. Aerospace Sciences Meeting \& Exhibit, 9-12 (2013).

8. Y.Z. Lin, Q.H. Xu, G.E. Liu. National Defense Industry Press, (2008).

9. W. Wang, W. Huang, Y. Cao, C. Gao. J. Therm. Sci. 27(6), 516-526 (2018). 